\title{
ANNOTATION
}

\section{Interaction of sense organs}

In the past musicians have believed that there is a close connexion between colour and tonality. In the score of the "Prometheus" symphony, Scriabine indicated the colour and light effects that should accompany the performance of this work. His idea was carried out on two occasions, once in Moscow and at another time in the United States. The finale of the symphony, which the composer conceived as a mighty crash of sound, he wanted accompanied by dazzling light. In this experiment the author was guided entirely by his own subjective emotion, and science, in the Soviet Union, is making valuable contributions to the study of the interaction of the sense organs. Wedensky, some years ago established the fact that music sounds louder to the auditor when the concert hall is flooded with light, and that the volume of sound lessens when the light is dimmed.

Soviet experimentalists have established that not only do visual irritants affect hearing, and auditory irritants, vision, but that the stimulation of any sensory organ, whether external or internal, may affect all other sense organs. Thus, visual irritants may heighten the sense of taste, sound irritants, temperature, taste and smell change, perception of colour.

Professor Kravkov, of Moscow, has found that the ability to perceive colour changes varies to a considerable degree if one warms one's hands or smells some odour, e.g., bergamot oil, or if one holds a lump of sugar in the mouth. It was found that in all these cases red, orange and yellow appear dimmer and are less visible, whereas green, blue and violet are intensified.

These facts, taken from an abstract which has been sent to us by "Russia To-day" Press Service, the Editor of which is Mrs. R. Townsend, may have a bearing on practical problems, e.g., motor driving, flying, etc.

\section{ABSTRACTS}

\section{I.-CONJUNCTIVA}

(1) Luo, T. H. (Peking).-Conjunctival lesions in tuberous sclerosis. Amer. Jl. of Ophthal. Vol. XXIII, p. 1029, 1940.

(1) Luo describes the case of a Chinese woman, aged 37 years, who was suffering from tuberous sclerosis. The palpebral conjunctiva of both lower lids and the left upper lid margin exhibited a 